\section{ABSTRACT}

Seeing is believing

Prevention is highly valued by both governments and civilians. Market parties have developed initiatives to accommodate this demand. Companies offer in the Netherlands prohibited Total Body Scans in Germany. Dutch physicians are sceptical about the quality and value of these tests. The first author has investigated the experiences and opinions of patients who had a preventive Total Body Scan. In this contribution we discuss the findings with respect to the recent attempt in the Dutch health care to prevent citizens from doing unnecessary and cost-generating tests by means of the Prevention Consult. Because consumers value outcomes that are obtained by medical techniques we question how the prevention consult can answer to the wishes of consumers.

Keywords: prevention, Total Body Scans, medical techniques, health risks

\section{LITERATUUR}

1. Assendelft P. De huisarts en health checks: van reactief naar pro-actief. Tijdschr Gezondheidswet 2010;88:103-4.

2. Broersen S. Preventie in de huisartsenpraktijk. Med Contact 2010;65:1544-6.

3. Thijsse S. Opgenomen in een moment. Een sociologisch onderzoek naar het gebruik van Total Body Scans, en de kracht van deze medische afbeelding van het lichaam. Amsterdam: Universiteit van Amsterdam, 2009.

4. Dijck van J. Het transparante lichaam. Medische visualisering in media en cultuur. Amsterdam: Amsterdam University Press, 2001.

5. Prescan, 2009. http://mens-en-gezondheid infonu $\mathrm{nl} /$ ziekten/18929-bodyscanpreventief-medisch-onderzoek.html

6. Gezondheidsraad. Screening. Tussen hoop en hype. Den Haag: Gezondheidsraad, 2008.
7. Omroep Gelderland. http://www.rtvgelderlandarchief.nl/index.php?datum $=150052009$ \&program$\mathrm{ma}=006 \& \mathrm{id}=57666$

8. Mol A. De logica van het zorgen. Actieve patiënten en de grenzen van het kiezen. Amsterdam: Van Gennep, 2006.

9. Tijmstra Tj. Leed voorkomen heeft een prijs. In: Zwieten van M, Kalden A (red). Ons gescreende lichaam. Kansen en risico's van de genetica.Amsterdam: Balans, 1999. p. 71-88.

10. Atkinson P. Reading the body. In: Nettleton S, Gustafsson U (eds). The sociology of health and illness reader.Oxford: Blackwell Publishers, 2002. p. 19-34.

11. Geest van der S, Have ten P, Nijhof G. De macht der dingen. Medische technologie in cultureel perspectief. Amsterdam: Het Spinhuis, 1994.

\section{CorrespondentieAdres}

Dr. Eric Vermeulen,

Vrije Universiteit Medisch Centrum, Community Genetics, Amsterdam,

tel. 020 - 4445970,

e-mail: e.vermeulen@vumc.nl

\title{
Gebrek aan aandacht voor cultuur binnen het gezondheidsgerelateerde onderwijs
}

Minne Bakker, ${ }^{1}$ Hanneke Felten, ${ }^{2}$ Katja van Vliet ${ }^{3}$

\begin{abstract}
De gezondheidszorg in Nederland is met de komst van de marktwerking meer gestandaardiseerd en geprotocolliseerd. ${ }^{1}$ Deze standaarden en protocollen hoeven geen probleem te zijn, mits ze gebruikt worden als richtlijnen en behandelaren ervan af durven te wijken. De standaarden zijn namelijk vaak in zekere mate gebaseerd op generaliserende statements voor de 'gemiddelde populatie'. Daardoor ontvangen groepen die afwijken van dit 'gemiddelde', zoals allochtone Nederlanders (noot a), soms niet de zorg die voldoet aan hun behoeften. Voorwaarde voor een goede behandeling is dat behandelaren en hulpverle-
\end{abstract}

\footnotetext{
1 Universiteit Utrecht, Utrecht

2 MOVISIE, Utrecht

3 Verwey-Jonker Instituut, Utrecht/TNO, Leiden
}

ners weten hoe ze rekening kunnen houden met interculturele verschillen. Dit lijkt nu nog niet altijd gegarandeerd. De kern van dit probleem ligt in de complexe samenhang tussen politiek, maatschappij en onderwijs. In de huidige situatie ontbreekt er kennis en aandacht binnen het gezondheidsgerelateerde onderwijs, waardoor nieuwe behandelaren onvoldoende voorbereid worden op de realiteit van de praktijk.
AANLEIDING
In 2000 publiceerde de Raad voor de Volksgezondheid en Zorg (RVZ) een ad- vies over de interculturalisatie van de gezondheidszorg. Uit dat advies bleek dat de zorg voor allochtone patiënten op

verschillende gebieden tekortschiet. ${ }^{2}$ Een van de oorzaken daarvan was het gebrek aan aandacht voor interculturaliteit binnen gezondheidsgerelateerde opleidingen. De RVZ gaf destijds al aan dat 'als van beroepsbeoefenaren verwacht wordt dat ze kunnen omgaan met cultuurverschillen, ze dan in de opleiding van de gezondheidszorg daarop moeten worden voorbereid en toegerust'. ${ }^{2}$ Het advies luidde daarom om in de toekomst meer integraal en structureel aandacht te besteden aan culturele diversiteit in het gehele curriculum. De vraag is in hoeverre dit advies is opgevolgd. Om een antwoord op die vraag te kunnen formuleren is er in opdracht van de Henny Verhagen Stichting (noot b) een inventariserend onderzoek uitgevoerd naar de mate van aandacht voor cultuur en/of gender binnen het gezondheidsgerelateerde ho- 
ger onderwijs (universitair en postdoctoraal) en wetenschappelijk onderzoek.

Deze inventarisatie liet zien dat er slechts 46 cursussen van de in totaal ongeveer 750 bekeken cursussen aandacht besteden cultuur (in sommige gevallen in combinatie met gender) op het gebied van gezondheidszorg. ${ }^{3}$ Veel van de cursussen die momenteel aangeboden worden, zijn facultatief. Dat houdt in dat het mogelijk is dat een deel van de studenten nauwelijks of geen cursussen volgt die specifiek ingaan op culturele diversiteit op het gebied van gezondheid.

\section{MARKTWERKING CENTRAAL}

Hoe is het mogelijk dat de RVZ tien jaar geleden al met adviezen kwam over de interculturalisatie van het gezondheidsgerelateerde onderwijs, en dat er tegenwoordig nog steeds zo beperkt aandacht is? Begin deze eeuw was er aanzienlijk meer aandacht voor cultuur binnen het gezondheidsgerelateerde onderwijs. Met de komst van de bachelor-master structuur is een groot deel van de interculturele vakken echter weer uit het curriculum verdwenen. Dit had onder andere te maken met de marktwerking binnen de universiteiten. Enkele decennia geleden heeft de marktwerking zijn intrede binnen het onderwijs gemaakt. ${ }^{4}$ Dit heeft ertoe geleid dat het onderwijs meer outputgericht is geworden, met als gevolg dat er met name cursussen aangeboden worden die goed 'verkopen' (met andere woorden; waar onder studenten veel animo voor is)..$^{5}$ In de afgelopen jaren is er binnen de geneeskunde en het geneeskundecurriculum erg veel vraag naar de 'harde', vaak toetsbare, kant van de wetenschap; de focus ligt vooral op nieuwe technieken, nieuwe medicijnen, nieuwe apparatuur. De meer 'softe', vaak subjectieve, kant, zoals de invloed van cultuur op gezondheid(szorg), de artspatiënt relatie en dergelijke, is momenteel minder populair. Binnen de psychologie is eenzelfde soort focus op de "harde' kant van de wetenschap waar te nemen; met de komst van het hersenonderzoek lijkt de psychologie zich meer op neuropsychologie en de biologische invalshoek te zijn gaan richten. Onder andere deze focus op de 'harde' kant van de wetenschap heeft ertoe geleid dat een deel van de interculturele vakken weer uit het curriculum zijn verdwenen; het was onvoldoende populair bij studenten.

Doordat er in de laatste jaren steeds minder aandacht is voor de invloed van cultuur op de gezondheid en zorg, lijkt er langzaam een structurele kennislacune te ontstaan op dit gebied. Docenten, onderzoekers en behandelaren die wel aandacht willen besteden aan diversiteit en gezondheid geven aan dat het gebrek aan kennis en cursus-/onderzoeksinstrumenten het vaak zeer bemoeilijken om interculturele cursussen te geven of onderzoeken te doen. ${ }^{3}$

\section{BELANG}

De overheid geeft aan dat alle burgers recht hebben op goede kwaliteit, toegankelijkheid en uitkomsten van zorg, maar lijkt er niet alles aan te doen om dit ook daadwerkelijk te bevorderen. De afgelopen jaren is het politieke klimaat omtrent allochtonen guurder geworden. Er lijkt een trend te zijn ontstaan waarin veel van allochtonen wordt verwacht (met name op het gebied van integratie), maar weinig voor deze groep wordt gedaan. Veel subsidies voor integratieprogramma's worden juist gekort. Het lijkt erop dat de overheid minder wil investeren in het bieden van gezondheidszorg die goed aansluit bij álle burgers; inclusief mensen met een migranten- of vluchtelingenachtergrond. Binnen de gezondheidszorg werkt deze houding echter averechts. Het gebrek aan aandacht voor de behoeften van allochtone $\mathrm{Ne}$ derlandsers binnen de zorg leiden juist tot hogere kosten. Dat heeft onder andere te maken met het feit dat deze groep Nederlanders over het algemeen meer problemen ondervinden bij het vinden van de juiste zorgverlening dat autochtonen. ${ }^{2}$ Daarnaast worden allochtone burgers vaak, wegens gebrek aan beschikbare kennis bij behandelaren, pas relatief laat correct gediagnosticeerd. Dat heeft te maken met het feit dat culturele achtergrond invloed heeft op de manier waarop klachten zich manifesteren. ${ }^{6}$ Daardoor kan het voor de behandelaar moeilijker zijn om een juiste diagnose te stellen. De behandelaar moet zich bewust zijn van de mogelijke verschillen tussen allochtone en autochtone
Nederlanders om tot een spoedige diagnose en behandeling te kunnen komen. Een gebrek aan deze kennis heeft binnen de Ggz bijvoorbeeld als gevolg dat allochtone patiënten regelmatig pas beginnen met een behandeling als de situatie al zeer ernstig is. ${ }^{7}$ Daardoor is er vaak een langduriger proces van herstel nodig is. Daar komen uiteraard hogere kosten bij kijken dan bij een kortdurende behandeling. Een ander veelvoorkomend probleem bij de behandeling van allochtone patiënten is dat deze vaak in mindere mate behandelingstrouw zijn. Een mogelijke oorzaak hiervan is dat de behandelingen minder goed aansluiten bij de behoeften en verwachtingen van de allochtone patiënten. Vermoedelijk slagen behandelaars er ook minder goed in om allochtone patiënten voor de behandeling te motiveren doordat de uitleg over de behandeling tekort schiet. Ook hier ligt het gebrek aan beschikbare kennis en vaardigheid van de behandelaar aan ten grondslag. Uitval van patiënten gedurende een behandeling is duur; er is al in de patiënten geïnvesteerd, maar het uiteindelijk beoogde resultaat van genezing is meestal nog niet bereikt.

\section{TOEKOMST}

Het gebrek aan kennis en vaardigheid lijkt het onmogelijk te maken om behandelingen voor allochtonen op korte termijn te verbeteren. Toch is er geen reden voor pessimisme. Er zijn, zo bleek uit het onderzoek van Bakker, ${ }^{3}$ immers wel verschillende cursussen die aandacht besteden aan cultuur op het gebied van gezondheid. Dat houdt in dat er bij een aantal personen en instellingen ook de nodige kennis is. Deze kennis moet behouden blijven en waar mogelijk uitgebreid worden. Het lijkt noodzakelijk om het belang van de aandacht voor cultuur - maar ook voor andere diversiteitsfactoren zoals gender, sociaal economische positie, opleidingsniveau en dergelijke op het gebied van gezondheid op verschillende terreinen duidelijker in kaart te brengen. Ideaal gezien zouden dergelijke diversiteitsfactoren opgenomen worden in de protocollen waar behandelaren mee werken. Waarschijnlijk zal de interesse naar betere zorg toenemen als 
uit harde cijfers blijkt dat het zo niet langer kan. We lijken nu in een vicieuze cirkel te zitten waarbij gebrek aan aandacht voor cultuur uiteindelijk leidt tot een gebrek aan passende behandelingen. $\mathrm{Er}$ is dus in de eerste plaats meer aandacht nodig om deze vicieuze cirkel te kunnen verbreken. Dan kan goede gezondheidszorg voor iedereen langzaam maar zeker een feit worden.

\section{NOTEN}

a Ook op het gebied van gender geldt vaak een bepaalde standaard (binnen de somatische zorg is dat vaak de man, binnen psychische zorg is dat vaak de vrouw). Ook op dit gebied kunnen de mensen die van de standaard afwijken een behandeling krijgen die minder goed aansluit bij hun behoeften.

b De Henny Verhagen Stichting stimuleert onderwijs en onderzoek op het gebied van gezondheid(szorg) en diversiteit (www.hennyverhagenstichting.nl). Het onderzoek was een afstudeeronderzoek in het kader van de master Arbeid, zorg en welzijn; beleid en interventie van de Universiteit Utrecht.

\section{ABSTRACT}

\section{Lack of attention for culture within} health related education

Due to the introduction of the market, the Dutch healthcare system has be- come more standardised in the last couple of years. These standards are mostly based on generalised statements about the 'mean population', which implies white man (or women in the mental healthcare). This means that groups that deviate from this standards, such as migrants, often do not get equally good healthcare as the mean population. A quick scan revealed that the problem of unequal healthcare in the Netherlands starts with a lack of attention for cultural factors in health related education. Future doctors do not receive structural education about differences in health beliefs and healthcare use of migrants. The lack of attention for the influence of culture on health and healthcare in this early stage, leads to a structural shortage of knowledge and skills about how to handle culture differences in healthcare. A possible explanation for this lack of attention for culture within the health related education is the current paradigm in the medical domain. There is a lot of attention for the 'scientific' side of healthcare, such as techniques to operate, but far less for the more 'soft' side of healthcare, such as communication between the doctor and the patient. This focus on the 'scientific' side of healthcare seems to have led to a decreasing number of courses that pay attention to cultural aspects of health and healthcare. To convince the market of the importance of attention for culture within healthcare, it seems necessary to (financially) prove it.

Keywords: healthcare, culture, migrants, medical education

\section{LITERATUUR}

1. Manna D. Standardisation in a multi-ethnic world: a paradox? Proefschrift. Rotterdam: Erasmus Universiteit Rotterdam, 2006.

2. Raad voor de Volksgezondheid en Zorg (RVZ). Interculturalisatie van de gezondheidszorg: advies uitgebracht door de Raad voor de Volksgezondheid en Zorg aan de minister van Volksgezondheid, Welzijn en Sport. Zoetermeer: RVZ, 2000.

3. Bakker M. Komt een Hindoestaanse vrouw bij de dokter: een inventariserend onderzoek naar de mate van aandacht voor cultuur en gender binnen het gezondheidsgerelateerde onderwijs en onderzoek. www.hennyverhagenstichting.nl/ masterscriptiem.bakker.pdf

4. Boomkens R. Topkitsch en slow science. Kritiek van de academische rede. Amsterdam: Van Gennep, 2008.

5. Lorenz C (red). If you're so smart, why aren't you rich? Universiteit, markt \& management. Amsterdam: Boom, 2008.

6. Seeleman C, Suurmond J, Stronks K. Een arts van de wereld. Etnische diversiteit in de medische praktijk. Houten: Bohn Stafleu van Loghum, 2005.

7. Berkum M van, Smulders E. Migranten, preventie en gezondheidszorg. Utrecht: Stichting Pharos, 2010.

CORRESPONDENTIEADRES Dr. K. P. (Katja) van Vliet, TNO, Postbus 2215, 2301 CE Leiden, e-mail: katja.vanvliet@tno.nl 